\title{
О ЛИТОЛОГИИ МОРЕН И ЛЕНТОЧНЫХ ГЛИН СО ДНА ВЯЙНАМЕРИ (ЗАПАДНАЯ ЭСТОНИЯ)
}

Литология морен и ленточных глин Эстонии хорошо изучена (Орвику, 1958; Раукас, 1961, 1978а, б; Пиррус, 1968 и др.). О литологии морен и ленточных глин со дна Вяйнамери, площадь которого около $2000 \kappa \mu^{2}$, можно говорить лишь предположительно по аналогии с сушей. В последние годы при изучении донных отложений Вяйнамери с помощью вибропоршневой грунтовой трубки собрана небольшая коллекция проб морен и ленточных глин с различных частей этого водоема '(рис. 1). Поскольку морены и ленточные глины дают основную часть кластического осадочного материала в состав морских отложений Вяйнамери, выяснение их литологии имеет немаловажное значение для решения некоторых седиментологических проблем в пределах указанного бассейна.

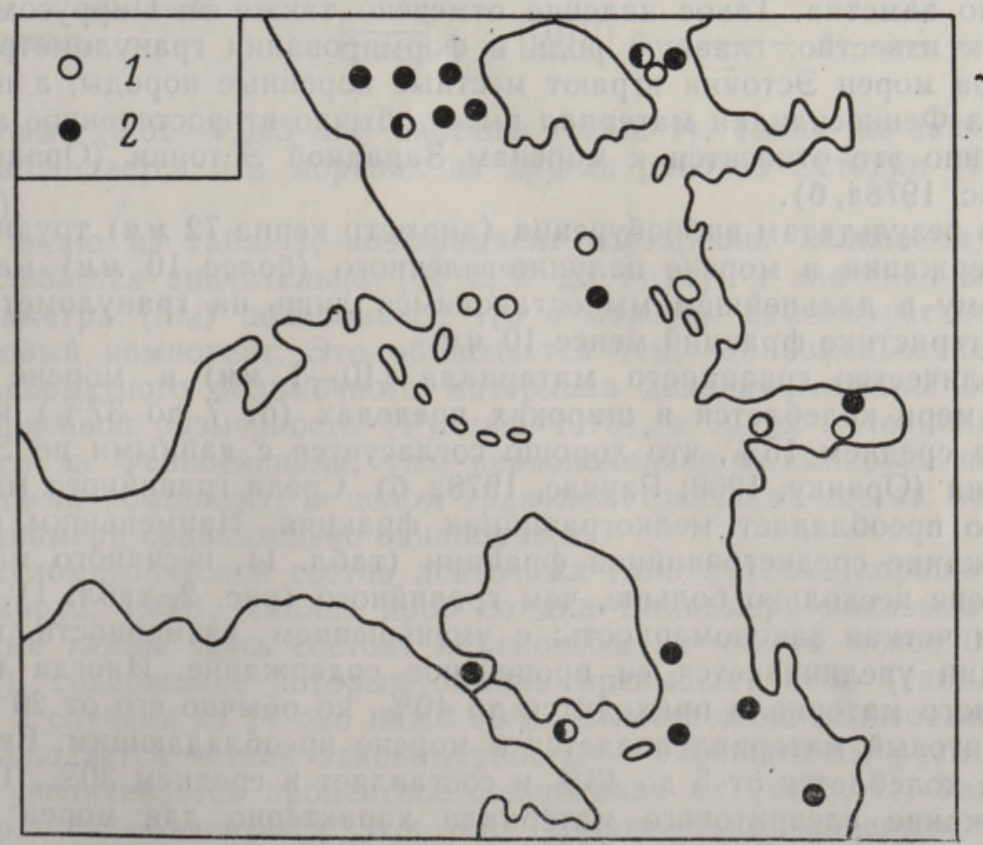

Рис. 1. Места отбора проб: 1 - ленточные глины; 2 - морены.

Основой для настоящей статьи послужили результаты анализа 14 проб ленточных глин и 18 проб морен из заложенных в Вяйнамери скважин (рис. 1). Морена обычно светло-серая, карбонатная, разно- 
Гранулометрический состав морен и ленточных глин дна Вяйнамери, \%

\begin{tabular}{|c|c|c|c|c|}
\hline \multirow{2}{*}{ Фракцин, мм } & \multicolumn{2}{|c|}{ Морены $(n=18)$} & \multicolumn{2}{|c|}{ Ленточные глины $(n=14)$} \\
\hline & Пределы & |Среднее & Пределы & |Среднее \\
\hline $\begin{array}{c}10-5 \\
5-2,5 \\
2,5-1 \\
1-0,5 \\
0,5-0,25 \\
0,25-0,1 \\
0,1-0,05 \\
0,05-0,01 \\
0,01-0,005 \\
0,005-0,001 \\
<0,001\end{array}$ & $\begin{array}{r}0-13,88 \\
0-10,01 \\
3,46-13,06 \\
3,07-13,44 \\
4,21-9,51 \\
4,67-28,90 \\
2,23-30,14 \\
2,13-23,82 \\
3,70-12,07 \\
4,01-26,56 \\
2,09-32,95\end{array}$ & $\begin{array}{r}5,51 \\
4,73 \\
6,78 \\
6,10 \\
7,39 \\
12,62 \\
15,32 \\
15,12 \\
7,42 \\
10,71 \\
8,30\end{array}$ & $\begin{array}{c}- \\
- \\
0-4,01 \\
0-3,20 \\
0-5,17 \\
0,12-10,29 \\
0,51-20,32 \\
0,06-32,68 \\
1,24-30,09 \\
10,77-43,59 \\
8,58-70,63\end{array}$ & $\begin{array}{r}\overline{-} \\
\overline{0}, 68 \\
0,44 \\
0,88 \\
2,31 \\
6,48 \\
12,92 \\
8,33 \\
23,84 \\
44,12\end{array}$ \\
\hline $\begin{array}{l}M_{d} \\
S_{0}\end{array}$ & $\begin{array}{r}0,0036-0,42 \\
2,38-11,14\end{array}$ & $\begin{array}{l}0,095 \\
5,94\end{array}$ & $\begin{array}{c}0,00095-0,063 \\
-\end{array}$ & $\frac{0,006}{-}$ \\
\hline
\end{tabular}

плотная, содержание валунно-галечного материала в ней колеблется в довольно широких пределах: от единичных мелких галек до $30 \%$. Ленточная глина светло-коричневая, реже сероватая, мощность годичных лент очень различна - от нескольких сантиметров до нескольких десятков сантиметров. Нередко во влажном виде годичную слоистость ленточной глины определить невозможно, однако после высыхания она хорошо заметна. Такое явление отмечено также Э. Пиррусом (1968).

Как известно, главную роль в формировании гранулометрического спектра морен Әстонии играют местные коренные породы, а принесенный из Фенноскандии материал имеет обычно второстепенное значение. Особенно это относится к моренам Западной Әстонии (Орвику, 1958; Раукас, 1978а, б).

По результатам вибробурения (диаметр керна 72 мм) трудно судить о содержании в морене валунно-галечного (более 10 мм) материала. Поэтому в дальнейшем мы остановимся лишь на гранулометрической характеристике фракций менее 10 мм.

Количество гравийного материала $(10-1$ мм в м морене со дна Вяйнамери колеблется в широких пределах (от 7 до 37\%) и составляет в среднем $15 \%$, что хорошо согласуется с данными по Западной Эстонии '(Орвику, 1958; Раукас, 1978a, б). Среди гравийного материала обычно преобладает мелкогравийная фракция. Наименьшим является содержание среднегравийной фракции (табл. 1), песчаного материала в морене несколько больше, чем гравийного (рис. 2, табл. 1). Наблюдается четкая закономерность: с уменьшением размерности песчаной фракции увеличивается ее процентное содержайие. Иногда на долю песчаного материала приходится до $40 \%$, но обычно его от 20 до $30 \%$. Алевритовый материал является в морене преобладающим. Его содержание колеблется от 5 до $43 \%$ и составляет в среднем $30 \%$. Такое же содержание алевритового материала характерно для морен Эстонии в целом (Раукас, Рейнтам, 1965; Раукас, 1978а, б).

Интересно отметить, что количество крупноалевритовых (0,10,05 мм) и мелкоалевритовых $(0,05-0,01$ мм) частиц в изученных моренах, как правило, почти одинаковое (табл. 1). Содержание пелитового материала в изученных пробах морен колеблется в очень широких пределах - от 12 до $65 \%$, но чаще всего составляет $17-30 \%$. Наиболее дефицитными среди пелитового материала являются круп- 
Рис. 2. Пределы изменения кривых распределения морен (1) и ленточных глин (2) и их оредние значения: 3 морены; 4 - ленточные глины.

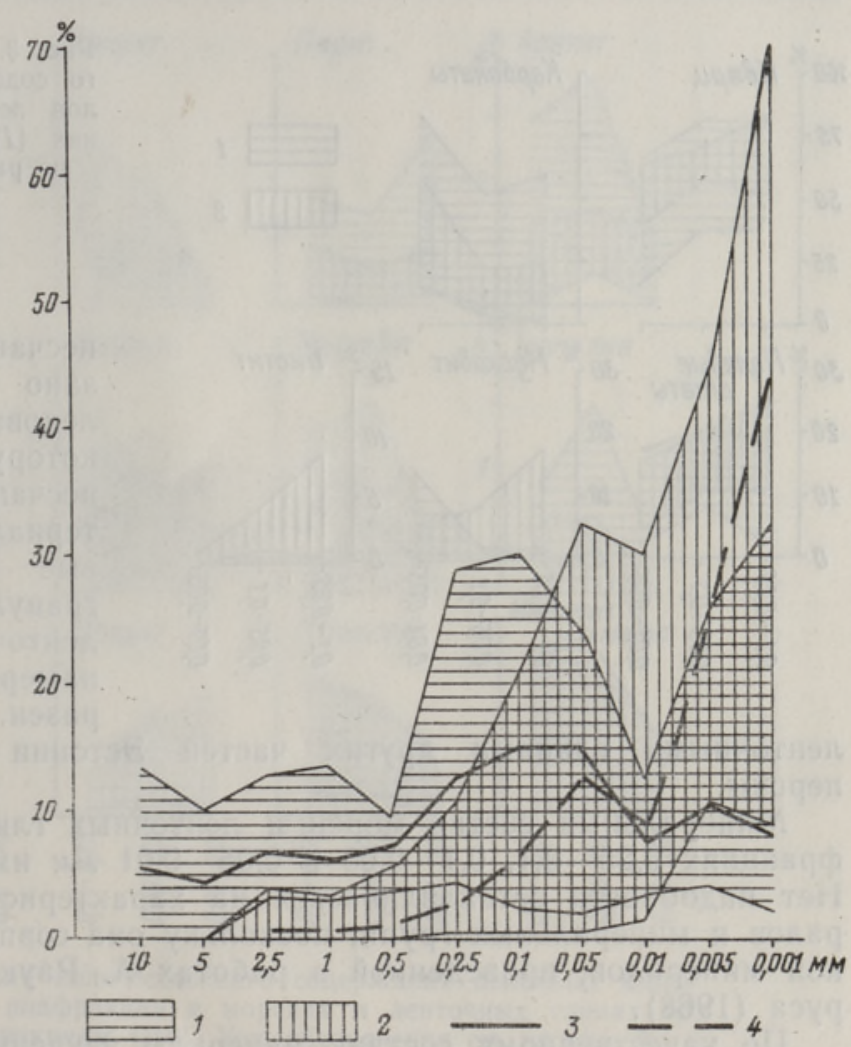

нопелитовые $(0,01-0,005$ мм) частицы (табл. 1$)$. Такая же закономерность наблюдается и в моренах из других районов Әстонии (Раукас, $1978 \mathrm{a}$, б).

Как видно из табл. 1, коэффициент сортировки мелкозема морен $\left(S_{0}\right)$ колеблется значительно (от 2,38 до 11,14 ), а значения медианного диаметра $\left(M_{d}\right)$ показывают, что в моренах доминирует песчаноалевритовый компонент. Это объясняется тем, что измельчение местного карбонатного обломочного материала доходит главным образом до алевритовой размерности (Рухина, 1973), а среди материала, принесенного из Фенноскандии, уже первоначально доминирует песчаноалевритовый компонент. В целом гранулометрический состав морен со дна Вяйнамери сравнительно однообразен.

Гранулометрический состав ленточных глин Эстонии хорошо известен (Пиррус, 1968). Анализ проб со дна Вяйнамери показывает, что ленточные глины здесь состоят в основном из частиц менее 0,01 мм (рис. 2), содержание которых обычно превышает $60 \%$ (табл. 1), и лишь в 2 случаях из 14 оно ниже $50 \%$. Относительно пелитовых фракций наблюдается четкая закономерность: с уменьшением размерности частиц увеличивается процентное содержание их (табл. 1). Такая закономерность объясняется тем, что кластические минералы имеют обычно размеры до мелкого алеврита, в то время как глинистые минералы редко бывают крупнее среднего пелита.

Содержание алевритовых, песчаных и гравийных зерен в изученных пробах ленточных глин колеблется в широких пределах (табл. 1, рис. 2), составляя в среднем '15-30\%. Особенно мало гравийных зерен (нередко полностью отсутствуют). Присутствие гравийного, а также 

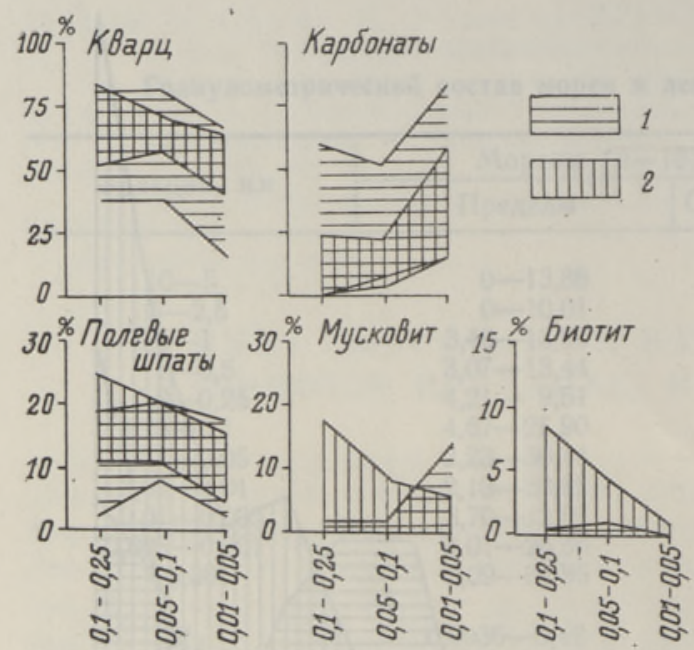

Рис. 3. Изменение количественного содержания основных минералов легкой подфракции в моренах (1) и ленточных глинах (2) по размерным фракциям (мм).

ленточными

глинами

других

песчаного материала связано главным образом с ледовым транспортом. Некоторую роль в транспорте песчано-алевритового материала играли также эоловые процессы. В целом гранулометрический состав ленточных глин дна Вяйнамери довольно однообразен. По сравнению с персны.

Минеральный состав морен и ленточных глин был исследован во фракциях $0,25-0,1,0,1-0,05$ и $0,05-0,01$ м. иммерсионным методом. Нет надобности останавливаться на характеристике отдельных минералов и минеральных групп, поскольку она совпадает с характеристикой минералов, приведенной в работах А. Раукаса (1961) и Э. Пирpyca (1968).

По качественному составу минералы изученных фракций морен и ленточных глин друг от друга не отличаются (табл. 2). Это вполне естественно, поскольку главным источником осадочного материала при образовании ленточных глин служили моренные отложения. Следовательно, минеральный состав морен и ленточных глин отражает главным образом соотношение карбонатных пород Әстонии и кристаллических пород Фенноскандии. Как видно и по рис. 3 и 4, более существенны количественные различия в минеральном составе изученных отложений. Определенные различия наблюдаются также в размерных фракциях.

Основная часть изученных фракций морен и ленточных глин состоит из легких минералов (кварца, полевых шпатов и карбонатов), на долю которых приходится обычно 95-98 вес. \% всей фракции. Тяжелых

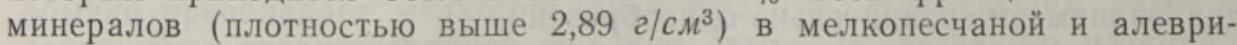
товых фракциях ленточных глин несколько больше, чем в тех же фракциях морен (табл. 2). С уменьшением размеров фракции увеличивается роль тяжелых минералов в ней. Наиболее высокое содержание тяжелых минералов отмечено в мелкоалевритовой фракции морен $(16,1 \%)$, что связано с концентрацией здесь карбонатных минералов. По нашим данным, выход тяжелых минералов из мелкопесчаной и алевритовых фракций морен значительно выше, чем по данным А. Раукаса (1961, $1978 \mathrm{a}$, б). Это объясняется тем, что морены дна Вяйнамери содержат обычно много карбонатных минералов, часть которых, попав в тяжелую подфракцию, сильно увеличивает ее содержание.

По рис. 3 и 4 видно, что отдельные минералы распределяются по размерным фракциям морен и ленточных глин по-разному. Количество кварца во фракциях ленточных глин почти во всех случаях несколько выше, чем в тех же фракциях морен (табл. 2 и рис. 3). При этом 


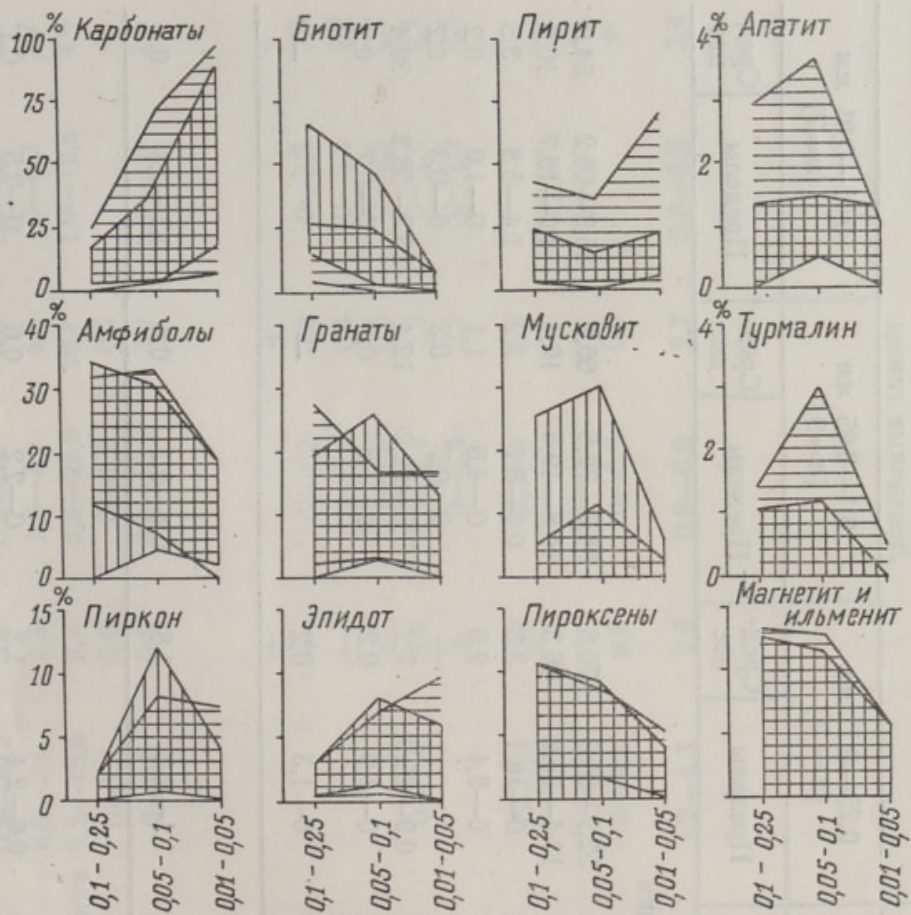

Рис. 4. Изменения количественного содержания основных минералов тяжелой подфракции в моренах и ленточных глинах по размерным фракциям (мм). Усл. обозначения см. на рис. 3.

содержание его в изученных фракциях морен более изменчиво. Наиболее богаты кварцем мелкопесчаная и крупноалевритовая фракции. Более отчетливо проявляется эта тенденция в моренах, где в мелкоалевритовой фракции сильно возрастает роль карбонатов (рис. 3). В мелкоалевритовой фракции ленточных глин, в которой карбонатов значительно меньше, чем в этой же фракции морены, уменьшение содержания кварца менее заметно. Аналогично кварцу в изученных пробах распределяются и полевые шпаты (рис. 3). Важно отметить, что содержание полевых шпатов в ленточных глинах несколько выше, чем в моренах, что хорошо согласуется с данными предыдущих исследований (Пиррус, Раукас, 1963; Пиррус, 1968).

Основное количество карбонатных минералов концентрируется в алевритовых фракциях (табл. 2). Особенно обогащена карбонатами мелкоалевритовая фракция морен, где их содержание нередко превышает $50 \%$. В ленточных глинах карбонатов меньше, чем связано с частичным истиранием и растворением карбонатных минералов в ходе переотложения моренного вещества. Количественное распределение карбонатов по размерным фракциям морен и ленточных глин сходное (рис. 3).

Слюды (табл. 2) встречаются в изученных пробах в несколько меньших количествах, чем в соответствующих отложениях из других частей Эстонии (Раукас, 1961; Пиррус, Раукас, 1963; Пиррус, 1968). Не исключено, что это связано с несколько отличающейся методикой гранулометрической обработки проб, в ходе которой отмучиванием пелитовых частиц удалялась и часть неосажденных слюдистых минералов. 


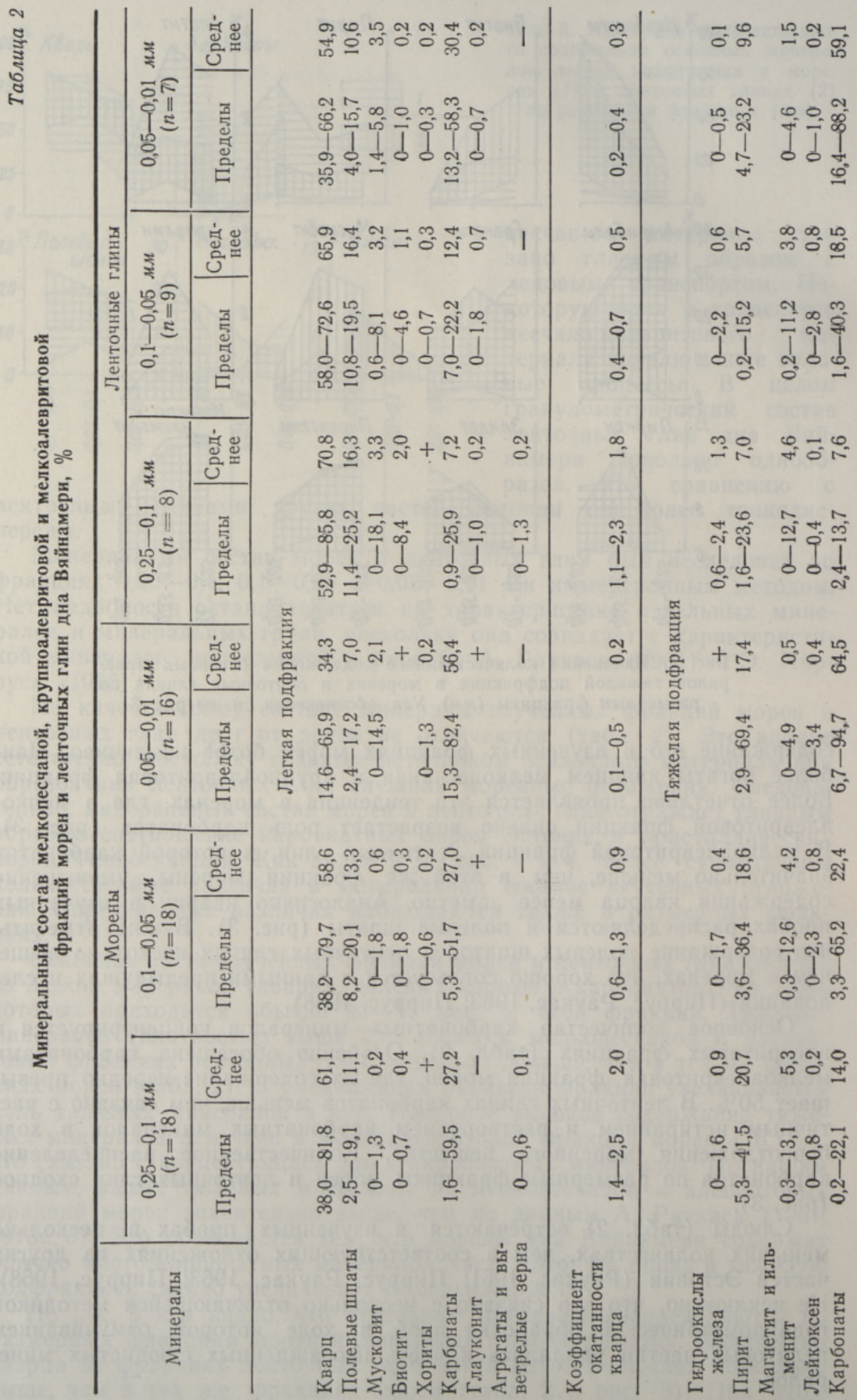


웅

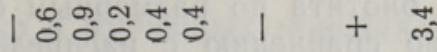

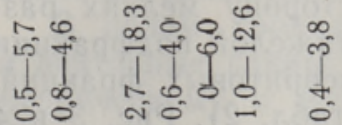

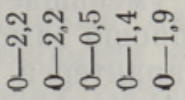

10
$\infty$
$\infty$
0
0

लำ

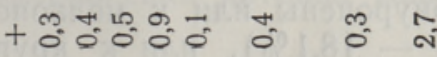

宅官灾

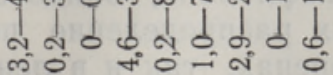

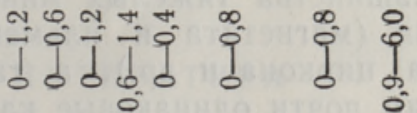

भिक

$++1+\ddot{0}+\stackrel{m}{0} \quad \stackrel{\infty}{0} \stackrel{0}{0}$

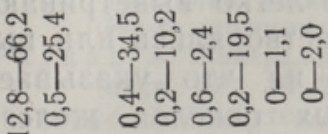

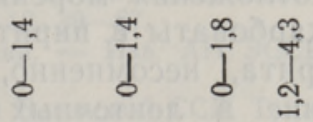

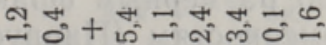

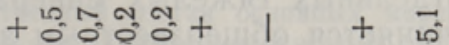

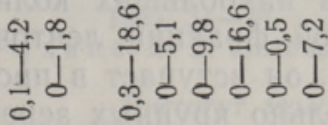

ग0

$\stackrel{\overrightarrow{6}}{-1}$

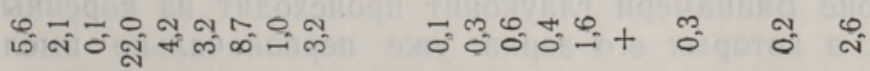

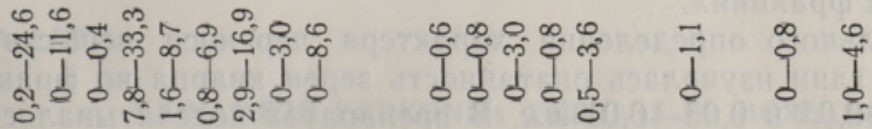

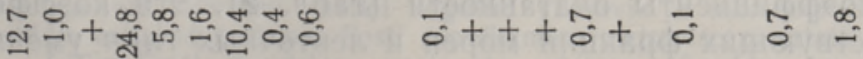

ली

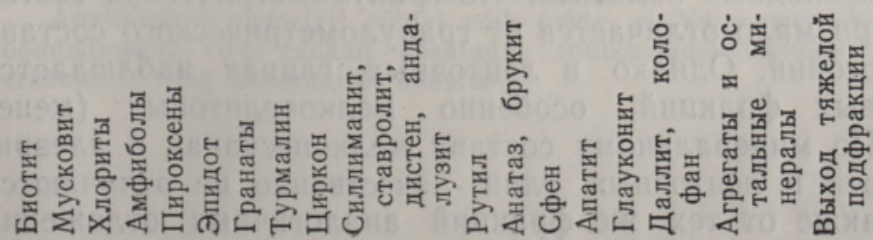


В распределении биотита по размерным фракциям отмечаются небольшие различия по сравнению с распределением его по данным Э. Пирруса и А. Раукаса (Пиррус, 1968; Пиррус, Раукас, 1963; Раукас, 1961, 1978а, б). Его содержание уменьшается в сторону мелких размерных фракций, что особенно хорошо заметно в тяжелой подфракции (табл. 2). Мусковит наиболее характерен для алевритовых фракций, особенно для мелкоалевритовой фракции морен (табл. 2). Рис. 3 и 4 неполностью отражают этот вывод, поскольку максимальные концентрации мусковита приурочены или к мелкопесчаной (легкая подфракция ленточных глин - 18,1\%), или к крупноалевритовой (тяжелая подфракция ленточных глин - 30,9\%) фракциям (табл. 2).

Содержание большинства тяжелых минералов из кристаллических пород Фенноскандии (магнетита и ильменита, амфиболов, эпидота, пироксенов, граната, циркона и др.), а также их распределение по размерным фракциям почти одинаковые как в моренах, так и в ленточных глинах (рис. 4, табл. 2). Апатита, турмалина, ставролита и дистена в моренах несколько больше. Минералы местных карбонатных пород (пирит и карбонаты) в моренах распространены заметно шире, чем в ленточных глинах (рис. 4, табл. 2). Это вполне понятно, поскольку в процессе переотложения моренного вещества легко выветривающиеся минералы (карбонаты и пирит) частично растворялись или выносились; часть пирита, несомненно, окислялась, на что указывает некоторое увеличение в ленточных глинах бурых окислов железа (табл. 2).

Распределение отдельных тяжелых минералов по размерным фракциям (табл. 2) подчиняется общеизвестным закономерностям (Пиррус, 1968; Раукас, 1961 и др.).

Иначе обстоит дело с глауконитом, который в наибольших количествах (до 1,9\%) встречается в мелкоалевритовой фракции ленточных глин (табл. 2). По данным А. Раукаса (1961), он вступает в процесс транспортировки в основном в виде сравнительно крупных зерен (песчаной размерности) и поэтому концентрируется в песчаных фракциях морен. В районе Вяйнамери глауконит происходит из коренных карбонатных пород, в которых его зерна уже первоначально имели алевритовую размерность, вследствие чего они и концентрировались здесь в алевритовых фракциях.

Для приблизительного определения характера переноса вещества морен и ленточных глин изучалась окатанность зерен кварца во фракциях $0,25-0,1,0,1-0,05$ и $0,05-0,01$ мм. В препаратах подсчитывалось по пятибальной шкале (от 0 до 4) приблизительно 150 зерен, по которым вычислялись коэффициенты окатанности (табл. 2). Эти коэффициенты для соответствующих фракций морен и ленточных глин уменьшаются в сторону мелких фракций. Как видно из табл. 2, в окатанности зерен кварца морены и ленточные глины существенных различий не имеют. Это свидетельствует о том, что ленточные глины образовались за счет переотложения моренного вещества без какой-либо существенной транспортировки.

В заключение необходимо отметить, что гранулометрический состав морен дна Вяйнамери мало отличается от гранулометрического состава морен Западной Эстонии. Однако в ленточных глинах наблюдается увеличение пелитовых фракций, особенно мелкопелитовых (менее 0,001 мм) частиц. По минеральному составу мелкопесчаная и алевритовые фракции морен и ленточных глин качественно не отличаются друг от друга, а также от тех же фракций аналогичных отложений 
Западной Әстонии. Однако в изученных моренах заметно выше содержание карбонатов и пирита, более часто встречается глауконит, особенно в мелкоалевритовой фракции ленточных глин.

В целом проанализированный материал показывает, что морены и ленточные глины дна Вяйнамери и прилегающей суши по гранулометрическому и минеральному составу существенно не различаются. Это позволяет использовать данные по аналогичным отложениям прилегающей суши для характеристики питания Вяйнамери терригенным осадочным материалом.

\section{ЛИТЕ Р А Т Р А}

Орвику К. К. Литологическое исследование морены последнего оледенения Эстонии количественными методами. - Тр. Ин-та геологии АН ЭССР, 1958, 3, $213-253$.

Пи р р ус Э. Ленточные глины Эстонии. Таллин, 1968.

Пи р р у с Э. А., Р а ук а с А. В. Сравнительная литолого-минералогическая характеристика мелких фракций морен и ленточных глин Эстонской ССР. - Tp. Ин-та геологии АН ЭССР, 1963, 12, 39-67.

Р а ук а с А. Минералогия морен Эстонии. - Изв. АН ЭССР, сер. физ.-мат. и техн. наук, 1961, 10, 244-258.

Р а ук а с А. Плейстоценовые отложения Әстонской ССР. Таллин, 1978а.

$\mathrm{P}$ a ук а с А. В. Об использовании некоторых литологических показателей для корреляции разновозрастных моренных горизонтов на примере Южной Эстонии. - В кн.: Вещественный состав основных морен. М., 1978б, 39-49.

Р а ук а с А. В., Р ейн т ам Л. Ю. Гранулометрический состав и некоторые физикохимические свойства основной морены последнего оледенения в Эстонии. В кн.: Литология и стратиграфия четвертичных отложений Эстонии. Таллин, $1965,31-44$.

Р у хин а Е. В. Литология ледниковых отложений. Л., 1973.

$\begin{array}{cc}\text { Институт геологии } & \text { Поступила в редакцию } \\ \text { Академии наук Эстонской ССР } & 21 / \mathrm{XI} 1979\end{array}$

21/XI 1979

\section{J. LUTT}

\section{VÄINAMERE PIIRKONNA VIIRSAVI JA MOREENI LITOLOOGIA}

Väinamerest viimaseil aastail kogutud viirsavi- ja moreeniproovide analüüsi põhjal on artiklis esitatud andmeid Eesti rannikumere pleistotseeni setete litoloogia kohta.

Lääne-Eesti mandriosa vastavate setetega vôrreldes on rannikumere moreenipeenese lõimisel vähe erinevusi, viirsavis on aga peliitse (alla $0,01 \mathrm{~mm}$ ), eriti peenpeliitse (alla $0,001 \mathrm{~mm}$ ) materjali osatähtsus suurem. Moreeni ja viirsavi peenliiva- ja aleuriidifraktsiooni mineraalne koostis ei erine märgatavalt teineteisest, samuti Lääne-Eesti analoogsete setete koostisest, küll aga on olulisi erinevusi mõningate mineraalide jaotumises. Näiteks on moreenis karbonaatide ja püriidi sisaldus tunduvalt suurem kui viirsavis, Lääne-Eesti mandriosa ja saarte moreenidega võrreldes esineb sagedamini glaukoniti, eriti viirsavi peenaleuriidifraktsioonis.

Analüüsitud materjali põhjal võib öelda, et Väinamerre kantava purdmaterjali iseloomustamisel võib edukalt kasutada rannikualadel levivate moreenide ja viirsavide terasuurust ning mineraalset koostist. 
J. LUTT

\section{ON THE LITHOLOGY OF VARVED CLAY AND TILL IN THE VÄINAMERI REGION}

In the course of the study of bottom deposits in recent years samples have been taken from varved clay and till underlying marine deposits. Up to now, data on the lithology of Pleistocene deposits within the Väinameri region were practically lacking. We hope that the 14 varved clay and 18 till samples analyzed will help to overcome this deficiency.

The granulometric composition of fine fraction of till differs from that of the West-Estonian continent and islands only slightly. However, in varved clay the pelitic (below $0.01 \mathrm{~mm}$ ), and especially the fine pelitic (below $0.001 \mathrm{~mm}$ ) material has been established in bigger amounts.

There are no notable differences in the qualitative mineral composition of fine sand and silt in till and varved clay, and also as compared to corresponding deposits in West Estonia. However, rather great quantitative differences are observable in the distribution of some minerals. Thus, in the till the content of carbonates and pyrite is higher than in varved clay. In comparison with the West-Estonian continent and islands, glaukonite is of a more frequent occurrence in the Väinameri region, especially in the fine silt fraction of varved clay. 